\title{
Psychological characteristics of Korean children and adolescents with type 1 diabetes mellitus
}

\author{
Eunhe Cho, MD, \\ Sang Hoon Shin, MD, \\ So-Hee Eun, MD, PhD, \\ Ji-Yeon Kim, \\ Hyo-Kyung Nam, MD, PhD, \\ Kee-Hyoung Lee, MD, PhD, \\ Young-Jun Rhie, MD, PhD \\ Departments of Pediatrics, \\ Korea University College of \\ Medicine, Seoul, Korea
}

\begin{abstract}
Purpose: This study investigates the behavioral and emotional characteristics of Korean children and adolescents with type 1 diabetes mellitus (T1DM) as compared to healthy controls, and examines whether their psychological status is associated with glycemic control, insulin regimens, or disease duration.

Methods: A total of 37 Korean children and adolescents with T1DM, aged 6-17 years, and 38 sex- and age-matched healthy controls were included in this study. Psychological distress was assessed using the Korean child behavior checklist (K-CBCL) and children's depression inventory (CDI) after the subjects and their parents were interviewed.

Results: The CDI and K-CBCL scores were significantly higher in T1DM subjects compared to normal controls. The T1DM subjects with "poorly controlled" blood glucose (glycosylated hemoglobin $\geq 8 \%$ ) and "old patients" (disease duration $\geq 1$ year) had a tendency to show higher CDI and K-CBCL scores. There were no significant differences in $\mathrm{CDI}$ and $\mathrm{K}-\mathrm{CBCL}$ scores between the intensive and conventional insulin therapy groups.

Conclusion: Children and adolescents with T1DM seem to have inferior psychological adjustment to their normal counterparts, which might be associated with glycemic control and disease duration. Psychological evaluation and intervention should be considered in the management of T1DM in children and adolescents.
\end{abstract}

Keywords: Type 1 diabetes mellitus, Diabetes, Psychosocial, K-CBCL, CDI
Received: 27 August, 2013 Revised: 13 September, 2013 Accepted:20 September, 2013

Address for correspondence: Young-Jun Rhie, MD, PhD Department of Pediatrics, Korea University Ansan Hospital, Korea University College of Medicine, 123 Jeokgeum-ro, Danwon-gu, Ansan 425-707, Korea

Tel: +82-31-412-4846

Fax: +82-31-405-8951

E-mail: human21@korea.ac.kr

\section{Introduction}

Type 1 diabetes mellitus (T1DM) is a chronic disease resulting from defects in insulin secretion and necessitating close attention to glucose monitoring, adherence to insulin regimens, and meal planning ${ }^{1)}$. Among individuals with comparable chronic disease, the course of a disease and treatment responsiveness may vary greatly. These differences may be due in part to the ways in which individuals cope with the disease and other stressful experiences. Depression is a serious health problem affecting a significant percentage of chronically ill persons ${ }^{2}$. Coping with T1DM can be very difficult, and these patients have an increased risk of greater psychiatric morbidity compared with the general population, with depression being the most commonly overlooked disturbance ${ }^{3)}$.

Adolescents with T1DM are at particular risk for depression ${ }^{2,4)}$. Depression is the single most common disorder in children and adolescents with $\mathrm{T}_{1} \mathrm{DM}^{5)}$, the prevalence of which is $20 \%$ in children and adolescents with T1DM, compared with 7\% in those without T1DM ${ }^{2}$. Concomitant challenges of puberty, peer pressure, self-identity, and increasing independence from parents result in a 10 -fold increase in suicide and suicidal ideation ${ }^{6,7)}$. It has been found that a person with T1DM and a psychiatric disorder is more likely to have poorly controlled $\mathrm{T}_{1 \mathrm{DM}}{ }^{8)}$. Depression, along with poor metabolic control, may result in more complications, poorer outcomes, and more frequent hospitalization ${ }^{9}$. Late adolescence has been identified as 
a period with a higher rate of acute complications and relative mortality risks for individuals with diabetes ${ }^{10)}$.

Therefore, psychological evaluation and intervention are important in the management of T1DM in children and adolescents because diabetes care could be compromised during this period. However, few studies have examined the impact of psychological characteristics on glycemic control in children and adolescents with T1DM.

In the present study, we investigate the behavioral and emotional characteristics of Korean children and adolescents with T1DM as compared to healthy controls, and examine whether their psychological status is associated with glycemic control, insulin regimens, or disease duration.

\section{Materials and methods}

\section{Subjects}

This study was based on an examination of 37 children with T1DM between the ages of 6 and 17 years, and 38 children without diabetes of comparable age and sex. The subjects were recruited from children and adolescents who visited the outpatient Pediatric Endocrinology Clinic of the Department of Pediatrics, Korea University Ansan Hospital in Gyeonggi-do, Korea.

\section{Methods}

Data were obtained through the administration of a questionnaire interview to subjects and their parents. Psychological distress was measured using the Korean child behavior checklist (K-CBCL) and the children's depression inventory (CDI). Glycemic control was assessed by glycosylated hemoglobin (HbAlc) level. Glycemic control was considered "well controlled" at $\mathrm{HbAlc}<8.0 \%$, and "poorly controlled" at $\mathrm{HbAlc} \geq 8.0 \%$. A patient was considered a "new patient" if his/ her disease duration was $<1$ year, or an "old patient" if his/her disease duration was $\geq 1$ year.

The K-CBCL was given to the parents in order to assess the children's psychological distress ${ }^{11)}$. The K-CBCL is a parentreport questionnaire with 119 items providing data on various emotional and behavioral problems found in children. The reliability and validity of the K-CBCL are well established in Korean children and adolescents ${ }^{12}$. A total problem behavior score was computed by summing the scores obtained for each item. Two broad-band syndromes (internalizing problems and externalizing problems) and nine clinical scales (withdrawn, somatic complaints, anxious/depressed, social problems, thought problems, attention problems, delinquent behavior, and aggressive behavior) were also produced. Externalized behavior problems are represented by attention problems and aggressive and delinquent behavior; internalized behavior comprises withdrawal, depressed behavior, and somatic complaints. The social functioning scale includes socialization and academic functioning. In the K-CBCL, the computed score is based on Korean normative samples, with the total problem behavior score computed by summing the scores obtained for each item $^{13)}$. Raw scores for each clinical factor are transformed into T-scores based on published norms (Available from: http:// www.cbcl.or.kr). In this study, T-scores $\geq 70$ were considered indicative of psychological distress.

The Korean version of the CDI, originating from Kovacs and Beck's Scale ${ }^{14,15)}$, was also used. It is a self-rated inventory test with 27 items providing quantification of depressive symptoms experienced over the previous 2 weeks. The normative data, factor structures, and reliability of the CDI were examined by Korean researchers ${ }^{16)}$. They found that the CDI mean scores for Korean children were higher than those in Kovac's original sample and that it was reliable and useful for measurements in children of different ages ${ }^{17-19)}$. Each of the 27 items is scored on a three-point scale ( 0 , absent; 1 , moderate; 2 , severe) reflecting the increasing severity of symptoms. In this study, patients with total CDI scores greater than 22 were considered having psychological distress.

\section{Statistical analyses}

All data were analyzed using the IBM SPSS ver. 20.0 (IBM Co., Armonk, NY, USA) Network version program. Differences among respondent groups were tested using the chi-square test, Student $t$-test, or analysis of variance. The data are expressed as mean \pm standard deviation unless otherwise indicated. $P$-values $<0.05$ were considered statistically significant.

\section{Ethics statement}

This study was approved by the Institutional Review Board of Korea University Ansan Hospital in Gyeonggi-do, Korea (IRB number AS13028). Written informed consents were obtained from all subjects and their parents.

\section{Results}

The clinical characteristics of the study subjects are shown in Table 1. There were no significant differences in sex distribution

Table 1. General characteristics of subjects

\begin{tabular}{lccc}
\hline Variable & T1DM $(n=37)$ & Normal control $(n=38)$ & $P$-value \\
\hline Age (yr) & $13.8 \pm 2.7$ & $12.7 \pm 3.1$ & 0.115 \\
Sex (male:female) & $18: 19$ & $19: 19$ & 0.907 \\
HbA1c (\%) & $9.1 \pm 2.0$ & & \\
Disease duration (yr) & $3.6 \pm 2.9$ & & \\
Insulin regimen & & & \\
$\quad$ Conventional & 23 & & \\
Intensive & 14 & & \\
\hline
\end{tabular}

Values are presented as mean \pm standard deviation.

T1DM, type 1 diabetes mellitus; HbA1c, glycosylated hemoglobin. 
and mean age between T1DM and normal control group. The mean HbAlc level of the T1DM subjects was $9.1 \% \pm$ $2.0 \%$. Twenty-three T1DM subjects were being treated with conventional insulin therapy, and 14 subjects were being treated with intensive insulin therapy.

Table 2 shows that CDI and K-CBCL total behavior problem scores were significantly higher in the T1DM subjects (CDI,: 13.0 \pm 8.5 ; K-CBCL total behavior problem scores, $49.6 \pm 12.3$ ) than in the normal control subjects (CDI, 6.5 \pm 5.6 ; K-CBCL total behavior problem scores, $41.9 \pm 7.8$ ).

A total of 10 T1DM subjects were classified as "wellcontrolled" subjects, and 27 as "poorly controlled" subjects. The difference in $\mathrm{HbAlc}$ between the well-controlled $(6.7 \pm 0.9)$

Table 2. Comparison of T-scores of CDI and K-CBCL between T1DM and normal control group

\begin{tabular}{lccr}
\hline Variable & T1DM $(n=37)$ & $\begin{array}{c}\text { Normal control } \\
(n=38)\end{array}$ & P-value \\
\hline CDI & $13.0 \pm 8.5$ & $6.2 \pm 5.6$ & $<0.001$ \\
K-CBCL & & & \\
Withdrawn & $51.0 \pm 10.0$ & $48.0 \pm 7.1$ & 0.180 \\
\hline Somatic complaints & $50.2 \pm 9.7$ & $46.3 \pm 6.0$ & 0.062 \\
Anxious/depressed & $49.8 \pm 11.0$ & $43.7 \pm 7.6$ & 0.014 \\
Internalizing problems & $49.6 \pm 11.4$ & $44.1 \pm 7.7$ & 0.032 \\
$\quad$ Social problems & $50.5 \pm 9.7$ & $46.0 \pm 7.8$ & 0.040 \\
Thought problems & $50.4 \pm 7.3$ & $48.4 \pm 5.5$ & 0.222 \\
$\quad$ Attention problems & $50.9 \pm 10.4$ & $45.0 \pm 7.5$ & 0.008 \\
$\quad$ Delinquent behavior & $51.4 \pm 10.1$ & $44.4 \pm 3.9$ & $<0.001$ \\
$\quad$ Aggressive behavior & $51.2 \pm 12.5$ & $42.1 \pm 7.8$ & $<0.001$ \\
\hline Externalizing problems & $51.1 \pm 12.4$ & $41.7 \pm 7.5$ & 0.001 \\
\hline Total behavior problems & $49.6 \pm 12.3$ & $41.9 \pm 7.8$ & 0.005 \\
\hline Val
\end{tabular}

Values are presented as mean \pm standard deviation.

CDI, children's depression inventory; $\mathrm{K}-\mathrm{CBCL}$, Korean child behavior checklist; T1DM, type 1 diabetes mellitus. and poorly controlled subjects $(10.1 \pm 1.5)$ was significant. CDI and K-CBCL total behavior problem scores were significantly higher in poorly controlled subjects (CDI, $13.9 \pm 8.3$; K-CBCL total behavior problem scores, $50.8 \pm 12.7)$ than in normal control subjects (CDI, 6.2 \pm 5.6 ; K-CBCL total behavior problem

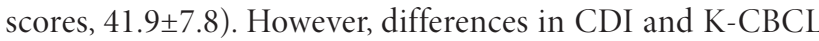
total behavior problem scores between the well-controlled and normal control subjects were not significant (Table 3 ).

A total of 9 T1DM subjects were classified as "new patient" subjects, and 28 as "old patient" subjects. CDI and K-CBCL total behavior problem scores were significantly higher in old patient subjects (CDI, 13.1 \pm 9.1 ; K-CBCL total behavior problems scores, $51.1 \pm 10.5$ ) than in normal control subjects (CDI, 6.2 \pm 5.6 ;

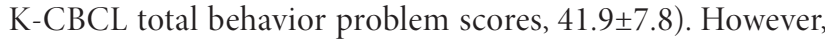
differences in CDI and K-CBCL total behavior problem scores between new patient and normal control subjects were not significant (Table 4).

There were no significant differences in CDI and K-CBCL total behavior problem scores between subjects receiving conventional and intensive insulin therapy (Table 5).

\section{Discussion}

In this study, we demonstrated that Korean children and adolescents with T1DM had higher CDI and K-CBCL total behavior problem scores than healthy controls. These findings suggest that children and adolescents with T1DM seem to have a higher risk of developing psychological distress. T1DM is the third most common chronic condition in children under 16 years of age $\mathrm{e}^{20)}$. Children and adolescents with T1DM are at high risk for psychosocial morbidities including depression, poor health-related quality of life, low self-efficacy, and difficulty with medical adherence and metabolic control ${ }^{21)}$. Adolescents with

Table 3. Comparison of T-scores of CDI and K-CBCL among "well-controlled”, "poorly controlled" and normal control groups

\begin{tabular}{|c|c|c|c|c|}
\hline Variable & Well-controlled $(n=10)$ & Poorly-controlled $(n=27)$ & Normal control $(n=38)$ & $P$-value for ANOVA \\
\hline Age (yr) & $12.0 \pm 2.5$ & $14.4 \pm 2.5^{\mathrm{a}, \mathrm{b})}$ & $12.7 \pm 3.1$ & 0.023 \\
\hline $\mathrm{HbA1c}(\%)$ & $6.7 \pm 0.9$ & $10.1 \pm 1.5$ & & $<0.001$ \\
\hline CDI & $10.7 \pm 8.8$ & $13.9 \pm 8.3^{\mathrm{a})}$ & $6.2 \pm 5.6$ & $<0.001$ \\
\hline \multicolumn{5}{|l|}{$\mathrm{K}-\mathrm{CBCL}$} \\
\hline Withdrawn & $49.7 \pm 11.4$ & $51.6 \pm 9.6$ & $48.0 \pm 7.1$ & 0.320 \\
\hline Somatic complaints & $50.9 \pm 9.3$ & $49.9 \pm 10.1$ & $46.3 \pm 6.0$ & 0.132 \\
\hline Anxious/depressed & $46.9 \pm 11.6$ & $51.1 \pm 10.7^{\mathrm{a})}$ & $43.7 \pm 7.6$ & 0.018 \\
\hline Internalizing problems & $48.6 \pm 11.8$ & $50.1 \pm 11.5$ & $44.1 \pm 7.7$ & 0.072 \\
\hline Social problems & $49.6 \pm 10.3$ & $50.9 \pm 9.7$ & $46.0 \pm 7.8$ & 0.116 \\
\hline Thought problems & $48.8 \pm 7.9$ & $51.1 \pm 7.2$ & $48.4 \pm 5.5$ & 0.297 \\
\hline Attention problems & $49.0 \pm 11.9$ & $51.8 \pm 9.8^{\mathrm{a})}$ & $45.0 \pm 7.5$ & 0.023 \\
\hline Delinquent behavior & $46.3 \pm 6.7$ & $53.7 \pm 10.7^{a, b)}$ & $44.4 \pm 3.9$ & $<0.001$ \\
\hline Aggressive behavior & $46.3 \pm 8.2$ & $53.5 \pm 13.6^{a)}$ & $42.1 \pm 7.8$ & 0.001 \\
\hline Externalizing problems & $45.8 \pm 8.6$ & $53.6 \pm 13.3^{\mathrm{a})}$ & $41.7 \pm 7.5$ & $<0.001$ \\
\hline Total behavior problems & $46.9 \pm 11.5$ & $50.8 \pm 12.7^{a)}$ & $41.9 \pm 7.8$ & 0.007 \\
\hline
\end{tabular}

Values are presented as mean \pm standard deviation.

$\mathrm{CDI}$, children's depression inventory; K-CBCL, Korean child behavior checklist; ANOVA, analysis of variance; HbA1C, glycosylated hemoglobin.

${ }^{\text {a) }} P<0.05$ compared with normal control. ${ }^{\text {b) }} P<0.05$ compared with well-controlled group. 
Table 4. Comparison of T-scores of CDI and K-CBCL among "new patient", "old patient" and normal control groups

\begin{tabular}{|c|c|c|c|c|}
\hline Variable & New patient $(n=9)$ & Old patient $(n=28)$ & Normal control $(n=38)$ & $P$-value for ANOVA \\
\hline Age (yr) & $11.3 \pm 2.5$ & $14.6 \pm 2.3^{a, b)}$ & $12.7 \pm 3.1$ & 0.003 \\
\hline Disease duration (yr) & $0.6 \pm 0.2$ & $4.5 \pm 2.7$ & & $<0.001$ \\
\hline $\mathrm{HbA1c}(\%)$ & $8.1 \pm 2.7$ & $9.5 \pm 1.7$ & & 0.069 \\
\hline CDI & $12.7 \pm 6.4$ & $13.1 \pm 9.1^{\mathrm{a})}$ & $6.2 \pm 5.6$ & 0.001 \\
\hline \multicolumn{5}{|l|}{$\mathrm{K}-\mathrm{CBCL}$} \\
\hline Withdrawn & $50.3 \pm 9.5$ & $51.2 \pm 10.4$ & $48.0 \pm 7.1$ & 0.363 \\
\hline Somatic complaints & $45.6 \pm 9.3$ & $51.6 \pm 9.5^{\mathrm{a})}$ & $46.3 \pm 6.0$ & 0.028 \\
\hline Anxious/depressed & $44.7 \pm 11.3$ & $51.4 \pm 10.6^{a)}$ & $43.7 \pm 7.6$ & 0.008 \\
\hline Internalizing problems & $45.0 \pm 11.6$ & $51.1 \pm 11.2^{a)}$ & $44.1 \pm 7.7$ & 0.026 \\
\hline Social problems & $49.0 \pm 8.6$ & $50.9 \pm 10.2$ & $46.0 \pm 7.8$ & 0.109 \\
\hline Thought problems & $48.3 \pm 8.3$ & $51.1 \pm 7.1$ & $48.4 \pm 5.5$ & 0.272 \\
\hline Attention problems & $48.4 \pm 13.2$ & $51.7 \pm 9.5^{\mathrm{a})}$ & $45.0 \pm 7.5$ & 0.021 \\
\hline Delinquent behavior & $50.9 \pm 13.4$ & $51.6 \pm 9.2^{\mathrm{a})}$ & $44.4 \pm 3.9$ & 0.001 \\
\hline Aggressive behavior & $48.6 \pm 17.6$ & $52.1 \pm 10.8^{a)}$ & $42.1 \pm 7.8$ & 0.002 \\
\hline Externalizing problems & $48.1 \pm 18.3$ & $52.1 \pm 10.3^{\mathrm{a})}$ & $41.7 \pm 7.5$ & 0.001 \\
\hline Total behavior problems & $44.7 \pm 16.7$ & $51.1 \pm 10.5^{\text {a) }}$ & $41.9 \pm 7.8$ & 0.004 \\
\hline
\end{tabular}

Values are presented as mean \pm standard deviation.

CDI, children's depression inventory; K-CBCL, Korean child behavior checklist; ANOVA, analysis of variance; HbA1c, glycosylated hemoglobin.

${ }^{\text {a) }} P<0.05$ compared with normal control. ${ }^{\text {b) }} P<0.05$ compared with new patient group.

Table 5. Comparison of $\mathrm{CDI}$ and $\mathrm{K}-\mathrm{CBCL}$ between conventional and intensive insulin therapy groups

\begin{tabular}{lccc}
\hline Variable & $\begin{array}{c}\text { Conventional } \\
(\mathrm{n}=23)\end{array}$ & $\begin{array}{c}\text { Intensive } \\
(\mathrm{n}=14)\end{array}$ & P-value \\
\hline Age (yr) & $13.5 \pm 3.0$ & $14.2 \pm 2.2$ & 0.594 \\
Disease duration (yr) & $2.9 \pm 2.7$ & $4.6 \pm 3.1$ & 0.091 \\
$\mathrm{HbA1C}(\%)$ & $9.1 \pm 2.0$ & $9.2 \pm 2.2$ & 0.913 \\
$\mathrm{CDI}$ & $13.5 \pm 8.3$ & $12.2 \pm 9.2$ & 0.520 \\
$\mathrm{~K}-\mathrm{CBCL}$ & & & \\
Withdrawn & $50.8 \pm 8.6$ & $51.6 \pm 13.3$ & 0.999 \\
Somatic complaints & $48.8 \pm 8.4$ & $53.2 \pm 12.1$ & 0.381 \\
Anxious/depressed & $49.1 \pm 114$ & $51.3 \pm 10.5$ & 0.636 \\
Internalizing problems & $48.8 \pm 10.4$ & $51.4 \pm 14.0$ & 0.493 \\
$\quad$ Social problems & $50.7 \pm 10.7$ & $50.0 \pm 7.7$ & 0.999 \\
$\quad$ Thought problems & $50.7 \pm 7.5$ & $50.0 \pm 7.4$ & 0.623 \\
$\quad$ Attention problems & $50.8 \pm 10.1$ & $51.2 \pm 11.5$ & 0.981 \\
$\quad$ Delinquent behavior & $49.9 \pm 8.0$ & $54.8 \pm 13.7$ & 0.418 \\
$\quad$ Aggressive behavior & $50.2 \pm 11.6$ & $53.7 \pm 14.6$ & 0.654 \\
Externalizing problems & $49.9 \pm 11.3$ & $54.0 \pm 15.0$ & 0.62 \\
Total behavior problems & $48.8 \pm 11.9$ & $51.3 \pm 13.6$ & 0.795 \\
\hline Values a presented as mean & &
\end{tabular}

Values are presented as mean \pm standard deviation.

$\mathrm{CDI}$, children's depression inventory; $\mathrm{K}-\mathrm{CBCL}$, Korean child behavior checklist; HbA1c, glycosylated hemoglobin.

T1DM are at increased risk for depression and anxiety, which can adversely affect diabetes management and quality of life ${ }^{22}$. Our findings are consistent with the results of these studies.

Although depression is a relatively common condition in patients with diabetes, its association with glycemic control has only recently been studied ${ }^{23)}$. A meta-analysis of 24 studies showed that depression in patients with diabetes was significantly associated with hyperglycemia in both type 1 and type 2 diabetes mellitus ${ }^{24)}$. There is evidence of associations between depression and higher HbAlc levels ${ }^{25)}$. Moreover, the remission of depression is associated with a reduction in $\mathrm{HbAlc}$ levels in diabetic patients ${ }^{19)}$. We found that CDI and K-CBCL total behavior problem scores were higher in poorly controlled subjects ( $\mathrm{HbAlc} \geq 8 \%$ ) than in normal control subjects. We also found that there were no differences in CDI and K-CBCL total behavior problem scores between well-controlled ( $\mathrm{HbAlc}$ $<8 \%)$ and normal control subjects. Therefore, it is assumed that T1DM patients with higher HbAlc seem to have a higher risk of developing psychological distress.

Given the relationship identified between depressive symptoms and $\mathrm{HbAlc}$ level, prospective research is needed to find the underlying mechanisms ${ }^{25}$. The relationship may be bidirectional with suboptimal metabolic control leading to depressed mood, and thus, to fewer self-management behaviors and inferior metabolic control ${ }^{23)}$.

In this study, we found that CDI and K-CBCL total behavior problem scores were higher in old patient subjects (disease duration $\geq 1$ year) than in normal control subjects. We also found that there were no differences in CDI and K-CBCL total behavior problem scores between normal control and new patient subjects (disease duration $<1$ year). These findings suggest that T1DM patients with longer disease duration seem to have a higher risk of developing psychological distress. However, the factors affecting psychological problems, including age, were not assessed nor controlled for in this study.

There were no significant differences in CDI and K-CBCL total behavior problem scores between conventional and intensive insulin therapy subjects. It is suggested that the number of daily insulin injections does not affect the risk of developing psychological distress.

This study has implications for clinicians, in that the risk of developing psychological distress was higher in the T1DM subjects. Therefore, it is suggested that clinicians need to pay 
attention to the psychosocial wellness of children with T1DM. It is further suggested that because the risk of developing psychological distress was related to glycemic control and disease duration, clinicians need to work to maintain reasonable levels of glycemic control and pay more attention to those who have had T1DM for longer than one year.

Psychological screening, appropriate intervention, and good metabolic control hold promise for early identification of, and may ultimately help prevent deterioration in, diabetes management ${ }^{22}$. For these reasons, diabetes clinicians should always be concerned about metabolic control, psychosocial prevention, and simple interventions that can be added to clinical encounters. The American Diabetes Association recommends that annual psychological screening should be part of routine best practice ${ }^{26)}$. Anderson ${ }^{27)}$ argues that diabetes teams should be aware of signs of depression in this age group, as undiagnosed and untreated depression can "contribute to a vicious cycle of adverse psychiatric and diabetes-related health problems" ${ }^{\text {"25) }}$. Therefore, it is important to be sensitive to the presence of depression and consider appropriate interventions.

In conclusion, there is need for an interest in psychological evaluation and intervention in the management of T1DM in children and adolescents. A possible limitation of this study was the relatively small sample size. Therefore, our findings should be validated by further evidence obtained from large-scaled studies.

\section{Conflict of interest}

No potential conflict of interest relevant to this article was reported.

\section{References}

1. Dantzer C, Swendsen J, Maurice-Tison S, Salamon R. Anxiety and depression in juvenile diabetes: a critical review. Clin Psychol Rev 2003;23:787-800.

2. Grey M, Whittemore R, Tamborlane W. Depression in type 1 diabetes in children: natural history and correlates. J Psychosom Res 2002;53:907-11.

3. Lustman PJ, Clouse RE. Depression in diabetic patients: the relationship between mood and glycemic control. J Diabetes Complications 2005;19:113-22.

4. Surís JC, Parera N, Puig C. Chronic illness and emotional distress in adolescence. J Adolesc Health 1996;19:153-6.

5. Kovacs M, Mukerji P, Iyengar S, Drash A. Psychiatric disorder and metabolic control among youths with IDDM. A longitudinal study. Diabetes Care 1996;19:318-23.

6. Goldston DB, Kelley AE, Reboussin DM, Daniel SS, Smith JA, Schwartz RP, et al. Suicidal ideation and behavior and noncompliance with the medical regimen among diabetic adolescents. J Am Acad Child Adolesc Psychiatry 1997;36:1528-36.

7. Goldston DB, Kovacs M, Ho VY, Parrone PL, Stiffler L.
Suicidal ideation and suicide attempts among youth with insulin-dependent diabetes mellitus. J Am Acad Child Adolesc Psychiatry 1994;33:240-6.

8. Lernmark B, Persson B, Fisher L, Rydelius PA. Symptoms of depression are important to psychological adaptation and metabolic control in children with diabetes mellitus. Diabet Med 1999;16:14-22.

9. Stewart SM, Rao U, Emslie GJ, Klein D, White PC. Depressive symptoms predict hospitalization for adolescents with type 1 diabetes mellitus. Pediatrics 2005; 115:1315-9.

10. Swerdlow AJ, Jones ME. Mortality during 25 years of follow-up of a cohort with diabetes. Int J Epidemiol 1996;25:1250-61.

11. Achenbach TM. Manual for the child behavior checklist 4-18 and 1991 profile. Burlington: University of Vermont Department of Psychiatry, 1991.

12. Oh KG, Lee HR. Development of Korean version of child behavior checklist (K-CBCL). Seoul: Korean Research Foundation Report, 1990.

13. Oh KG, Hong KM, Lee H, Ha E. K-CBCL. Seoul: Chung Ang Aptitude Publishing Co., 1997.

14. Kovacs M, Beck AT. An empirical clinical approach toward a definition of childhood depression. In: Schulterbrandt JG, Raskin A, editors. Depression in children: diagnosis, treatment and conceptual models. New York: Raven Press, 1977.

15. Kovacs M. The children's depression inventory: a self-rated depression scale for school-aged youngsters. Pittsburg: University of Pittsburg School of Medicine, 1983.

16. Cho SC, Lee YS. Development of the Korean form of the Kovacs children's depression inventory. J Korean Neuropsychiatr Assoc 1990;29:943-56.

17. Saylor CF, Finch AJ Jr, Spirito A, Bennett B. The children's depression inventory: a systematic evaluation of psychometric properties. J Consult Clin Psychol 1984;52:955-67.

18. Myers K, Winters NC. Ten-year review of rating scales. I: overview of scale functioning, psychometric properties, and selection. J Am Acad Child Adolesc Psychiatry 2002;41:114-22.

19. Kovacs M, Goldston D, Gatsonis C. Suicidal behaviors and childhood-onset depressive disorders: a longitudinal investigation. J Am Acad Child Adolesc Psychiatry 1993;32:8-20.

20. Betts P, Buckley M, Davies R, McEvilly E, Swift P. The care of young people with diabetes. Diabet Med 1996;13(9 Suppl 4):S54-9.

21. Fogel NR, Weissberg-Benchell J. Preventing poor psychological and health outcomes in pediatric type 1 diabetes. Curr Diab Rep 2010;10:436-43.

22. Whittemore R, Jaser S, Chao A, Jang M, Grey M. Psychological experience of parents of children with type 1 diabetes: a systematic mixed-studies review. Diabetes Educ 2012;38:562-79. 
23. Lustman PJ, Anderson RJ, Freedland KE, de Groot M, Carney RM, Clouse RE. Depression and poor glycemic control: a meta-analytic review of the literature. Diabetes Care 2000;23:934-42.

24. Lustman P, Carney R, Amado H. Acute stress and metabolism in diabetes. Diabetes Care 1981;4:658-9.

25. Johnson B, Eiser C, Young V, Brierley S, Heller S. Prevalence of depression among young people with Type 1 diabetes: a systematic review. Diabet Med 2013;30:199-208.

26. Silverstein J, Klingensmith G, Copeland K, Plotnick L, Kaufman F, Laffel L, et al. Care of children and adolescents with type 1 diabetes: a statement of the American Diabetes Association. Diabetes Care 2005;28:186-212.

27. Anderson BJ. Living with depression and type 1 or type 2 diabetes in late adolescence and young adulthood: lessons from research. Diabetes Spectrum 2010;23:32-7. 